\title{
Continent urinary diversion with short appendices in obese patients: the initial results of a surgical option
}

\author{
Marcelo Ferreira Cassini ${ }^{1, ~ *}$, Antônio Antunes Rodrigues Júnior ${ }^{1}$, \\ Carlos Augusto Fernandes Molina ${ }^{1}$, Adauto José Cologna ${ }^{1}$, Alessandra Mazzo ${ }^{2}$, \\ SílvioTucci Júnior ${ }^{1}$ \\ ${ }^{1}$ Division of Urology, Department of Surgery and Anatomy, Faculty of Medicine of Ribeirao Preto, University of Sao Paulo, Brazil \\ ${ }^{2}$ Faculty of Nursing, of Ribeirao Preto, University of Sao Paulo, Brazil
}

\section{Email address:}

marcelo.cassini@globo.com(M. F. Cassini), aantunesrj@yahoo.com.br(A. A. Rodrigues Jr.), cafmolina@gmail.com(C. A. F. Molina), ajcologn@fmrp.usp.br(A.J. Cologna), amazzo@eerp.usp.br(A. Mazzo), stucci49@gmail.com(S. Tucci Jr.)

\section{To cite this article:}

Marcelo Ferreira Cassini, Antônio Antunes Rodrigues Júnior, Carlos Augusto Fernandes Molina, Adauto José Cologna, Alessandra Mazzo, SílvioTucci Júnior. Continent Urinary Diversion with Short Appendices in Obese Patients: the Initial Results of a Surgical Option. Journal of Surgery. Vol. 1, No. 2, 2013, pp. 22-27. doi:10.11648/j.js.20130102.14

\begin{abstract}
Introduction: Many patients need to be submitted to a continent urinary derivation surgery. Lost of bladder compliance secundary to neurogenic bladder injuries, severe and untractable urethral stenos is are some of the main indications. We present here the initial results and outcomes of twelve procedures performed using the association between Mitrofanoff's principle and Monti's technique as a surgical option for a continenturinarydiversion in patients with short appendices or obese. Materials and Methods: We analyzed data from twelve patients who were submitted to ileocistoplasty and urinary continent derivation by association between Mitrofanoff's principle and Monti's technique performed from january2009 to december 2012 in our institution. In all patients the appendices were too short to reach the skin, some of them, because the obesity. Results: Twelve patients were submitted to the Mitrofanoff and Monti techniques association. The most common surgical complications were stoma skin stenosis ( 02 cases) and urinary leakage through the re-opened bladder neck in 02 patients. Urinary infection (01 sepse) was the main clinical complication. Eleven patients are totally adapted to intermittent clear catheterization through the naveland satisfyed with urinary continence and quality of life.There were no deaths and no urinary or intestinal fistulas secondary to the procedure. Conclusions: The association between Mitrofanoff's principle and Monti's technique is safe, feasible and a very useful alternative in urologic cases, (i.e., severe and untractable urethral stenos is and low compliance neurogenic bladder, for example) of continent urinary diversion, when the ileocecal appendix is too short to reach the skin (i.e., obese patients).
\end{abstract}

Keywords: Mitrofanoff, Principle, Monti, Technique, Bladder Augmentation, Urethral Stenosis, Continent Urinary Diversion

\section{Introduction}

The management of neurogenic miccional dysfunction and urinary incontinence has been revolutionized by the introduction of clear intermittent catheterization (CIC) by Lapides in $1972^{(1)}$, and later, by the description of the "trans-appendicular continent cystostomy" by Mitrofanoff in $1980^{(2)}$. Mitrofanoff launched a new concept whereby the bladder could be emptied by a route other than the urethra. This concept led to the publication of many alternatives to the appendix conduit, including the transverse ileal (YangMonti) ${ }^{(3,4)}$ tube, and conduits constructed from ureter,
Fallopian tube, tabularized preputial transverse island flap, and longitudinally tabularized ileal and gastric segments. Further experience with the procedure, and the onset of complications such as stomal stenosis and leakage, instigated the description of various stomal options and conduit implantation techniques. More recently, laparoscopic and robotically assisted techniques have also been performed. ${ }^{(5)}$

Hydronephrosis, reflux and renal failure are serious complications that occur in patients with neurogenic overactive bladder. Such patients should be treated starting in childhood with clean and intermittent catheterization along with anticholinergics in the presence of detrusor 
overactivity. In severe cases (i.e., sphincter dyssynergia), there are greater risks of renal failure ${ }^{(6)}$. When,irrespective of the treatment, the patient has an unsatisfactory outcome and the bladder compliance is lost, it is imperative to carry out surgery aimed at reducing bladder storage pressure. ${ }^{(7)}$ Our serviceroutinely usesileocystoplasty and, for patients unable or not adapted to intermittent catheterization, the Mitrofanoff's principle is used to form a continent stoma (in which the vascularized ileocecal appendix is anastomosed at the skin and bladder, with a nonrefluxing valve and continent stoma). After, we perform the closure of the bladder neck in the urinary incontinent patients with leak point pressure $<20 \mathrm{cmH}_{2} \mathrm{O} .{ }^{(7)}$ This procedure is also a good alternative for severe and intractable urethral stenosis. ${ }^{(8)}$

Some times during the surgery, it is found a short ileocecal appendix that is insufficient to reach the skin (i.e., obese patients). In 2011, Rodrigues Jr.et al. published a case report ${ }^{(7)}$ using the Monti's technique (an ileal segment of $2-3 \mathrm{~cm}$ that is open longitudinally and reconfigured transversally, moldeled by a 12-Fr urethral cateter) associated with the Mitrofanoff's principle to solve this problem.

Now, we present here the initial results and outcomes of the last 12 procedures performed in our institution, using the association between the Mitrofanoff's principles and Monti's technique in obese patients or those with short ileocecal appendices, unable to reach the skin.

\section{Materials and Methods}

We analyzed data from twelve adult patients who were submitted to ileocistoplasty and urinary continent diversion by association between Mitrofanoff's principle plusMonti's technique, as idealized by Rodrigues Jr., ${ }^{(7)}$ performed from January 2009 to December 2012 in our institution. Patients with neurogenic bladder who were submitted to this procedure had unsatisfactory clinical progression despite treatment with intermittent catheterization and anticolinergics. Others not suitables for catheterization, developed low bladder compliance $\left(<12,5 \mathrm{~mL} / \mathrm{cmH}_{2} \mathrm{O}\right)$, some of them with vesicoureteral reflux, although their renal function was still preserved, and bladder augmentation (ileocystoplasty) was indicated. Patients with urethral stricture and considered for continent urinary diversion were initially submitted to the traditional techniques of urethroplasty with bad outcomes.

Surgical technique:The patients have been hospitalized 24 hours before surgery and started on a liquid diet without waste, and fasting of 8 hours preceding the procedure. Appropriative preoperative planning is required to position the skin incision to allow adequate mobilization of the appendix to the bladder. This can be achieved through a low midline incision. Mobilization of the ascending colon along the line of Toldt may be required to gain mobilization of the appendix and its mesentery.Once the cecum has been mobilized the base of the appendix is amputated, leaving a small cuff of cecum with the appendix. Use of the cuff at the stoma may decrease the risk of stenosis. The cecum is closed in a fashion similar to an open appendectomy.

To perform the bladder augmentation, it was used $15 \mathrm{~cm}$ of ileum, $20 \mathrm{~cm}$ from the ileocecal valve, that was opened longitudinally and reconfigured into a " $U$ " shape(ileocystosplasty), with continent derivation (Mitrofanoff's principle). A location is selected for implantation of the appendix into the bladder. The location is based on the length of the appendix, the mobility of the bladder, and the location for the appendix stoma. Typically, the distal end of the appendix is tunneled into a posterolateral position within the bladder. The appendix should be brought up to reach the skin without tension, and care must be taken no to twist the pedicle or to occlude it as it passes through the abdominal wall fascia. The base of the appendix often can be hidden within the umbilicus, which allows elimination of a small but obvious abdominal stoma. For prevention of kinking and problems with catheterization, it is advisable to maintain as short a conduit as possible.

During the surgeries, we found shorts ileocecal appendices (or obese patients) that were insufficient to reach the skin. Then it was decided (as idealized by Rodrigues $\mathrm{Jr}^{(7)}$ )to make an association between the Mitrofanoff's principle and the Monti's technique of ileal conduit by which we performed an anastomosis of distal stump of the appendices to the bladder with an antireflux valve. After, the proximal stump of the appendices was anastomosed to an ileal segment of $2.0 \mathrm{~cm}$ that was open longitudinally and reconfigured transversally (Monti technique), modeled by a 12-Fr urethral catheter, and finally, the distal stump was sutured at the patient's navel. A security suprapubiccystostomy (22-Fr) was performed and a Foley catheter (12-Fr) was left through the continent conduit for 21 days and then, thebladder neck was closured in two layers using 2.0 Vicryl, in urinary incontinent patients with leak point pressure $<20 \mathrm{cmH}_{2} \mathrm{O}$.

In general, the diet was released from the third day postoperatively and gradually progressed. The patients were discharged between the sixth and tenth postoperative day. Patients in our center have an indwelling catheter through Mitrofanoff (12-Fr Foley catheter) and a suprapubic catheter (22-Fr Foley), both of which are initially left on free drainage.

The patientswere discharged home with both catheters in situ for 4 weeks, the Mitrofanoff catheter being spigotted to avoid accidental expulsion and damage to the conduit. The patients are prescribed regular anti-cholinergic medication (e.g. oxybutinin) in order to reduce bladder spasms. After this period, the patient is brought back to the ward, where the Mitrofanoff catheter is removed, and the family trained to perform CIC. Once CIC is established, the suprapubic catheter is taken out. The patients are normally advised to catheterize every 6 hours during the day, and should be able to stay dry overnight if their reservoir is of appropriate capacity and compliance. 


\section{Results}

Twelvepatients (10 males and 2 females) were submitted to the procedure as described above, three of them had untractable urethra stenosis, 09 with low compliance neurogenic bladder (05raquimedular trauma and 04 myelomeningoceles), (Table 1).

The three patients with urethral stricture had been previously treated unsuccessfully with urethroplasties (2-3 procedures each). All of the urethral strictures were posttraumatic and associated with hip fracture. The patients were using a suprapubic catheter.

Although the renal function of patients was still preserved, the bladder augmentation was indicated preventively because of the lost of its compliance.

Table 1. Showing all the indications of the association between Mitrofanoff procedure and Monti's technique.

\begin{tabular}{l}
\hline Association: Mitrofanoff + Monti \\
\hline NeurogenicBladder(9) \\
- Raquimedular Trauma (5) \\
- Myelomeningocele(4) \\
Severe Urethral Stenosis (3) \\
Total 12 Cases* \\
\hline
\end{tabular}

*(12 appendices did not reach the skin at navel level)

The ileocecal appendices of all these patients were too short and did not reach the skin (navel), main reason to perform the association between Mitrofanoff'sprinciplewith Monti's technique(as idealized by Rodrigues Jr. ${ }^{(7)}$ ).

Table 2. Showing the complications of association betweenMitrofanoff procedure plus Monti's technique.

\begin{tabular}{lc}
\hline \multicolumn{2}{c}{ Association: Mitrofanoff + Monti } \\
\hline Complications: & Number of Patients \\
& \\
Clinical Treatment: & 01 \\
Urinary Sepse & \\
& \\
Surgical Treatment: & 02 \\
Stoma Stenosis (skin) & 02 \\
Opening of Bladder Neck (leakage) & 01 \\
Bladder lithiasis & 01 \\
Ureteral lithiasis & 01 \\
Abdominal wall (resuture) & \\
& \\
No Deaths or Fistulas & \\
\hline
\end{tabular}

The outcome of patients and more common complications are shown in table 2. Eleven patients are totally adapted to the intermittent clear catheterization and satisfyed with the urinary continence (no leakage), and their quality of life, without pads, no cystostomy tubes and no indwelling catheter. One patient developed urinary sepsis at $21^{\circ}$ post-operative day after removed thecystostomy. He was conservatively treated with antibiotics and clinical life support, with good outcome. Two patients had stoma (skin of the navel) stenosis, corrected with a circular incision and fibrosis resection.

In nine patients we performed the bladder neck closure because severe urinary incontinence and leak point pressure less than $20 \mathrm{cmH} 2 \mathrm{O}$. Two patients of them had late reopening of the bladder neck, despite of the closure in two layers, being submitted to a new surgical approach; one had good outcome, however the other (a female), even after three reoperations, remained with an open bladder neck and urinary leakage. This patient, several months later, had a right ureteral lithiasis, been underwent to a laser transureteroscopy lithotripsy and pig-tail implantation. Another patient with a large bladder lithiasis formation was underwent to open cystolitotomy.

There were no deaths and no urinary or intestinal fistulas secondary to the procedure.

\section{Discussion}

The Mitrofanoff principle, originally described in $1980^{(2)}$, has been a mainstay in the armamentarium of pediatric urologists and reconstructive surgeons for creation a continent catheterizable stoma using the appendix. This principle involves the use of a small-caliber tube (appendix) implanted into a compliant bladder or resevoir with a nonrefluxing anastomosis to provide a convenient and effective method of emptying the bladder. ${ }^{(7)}$ The concept of an antirefluxing tunnel was borrowed from the ureteral reimplantation technique described by Coffey in 1911. ${ }^{(9)}$

Monti's tube offers a Mitrofanoff-based alternative. It was first described by Eshghi in $1986^{(10)}$ but was popularized by Monti et al. ${ }^{(4)}$ and Yang et al. ${ }^{(3)}$ About 2-3 $\mathrm{cm}$ of ileum are incised longitudinally opposite the mesenterium and subsequently transversally retubularized to create a pedicled tube of 18 Fr lumen up to 9-cm long. This procedure is technically easy, and the small part of ileum it requires is always available. ${ }^{(1)}$ These techniques are useful for continent urinary derivation in patients with untractable urethral stenosis and low compliance neurogenic bladder.

Nowadays, there is a remarkable increase in obesity of patients around the world. Thus, the ileocecal appendices may be too short to reach the skin. As an alternative to solve this problem, Rodrigues Jr. et al. ${ }^{(7)}$ reported a case in 2011, of successful association between Mitrofanoff principle and Monti's technique. Now, we report here the initial results of 12 procedures performed in obese patients or those with short ileocecal appendices, submitted to a 
continent urinary diversion. The adipose tissue of the abdomen in obese patients is very thick, and the appendix could be too short to reach the skin, even at the right iliac fossa. Another relevant fator is that the navel's skin, naturally already through the abdominal wall, facilitates the anastomosis with the continent conduit, making the patient's abdomen more aesthetically pleasing. ${ }^{(7)}$

Problems with Mitrofanoff catheterization are common and may be due to narrowing at skin level or problems within the channel. This explains the variety of stomal sites and techniques used to fashion the anastomosis to the skin. ${ }^{(5)}$

The main problem experienced by patients was difficult catheterization through the continent catheterizable channels. Although most problems occurred in the first 12 months after operation, we have a patient experiencing new difficulties even 3 years after the original operation. The majority of catheterization problem was due to skin-level stenosis and occurred with similar frequency for umbilical stomas. There appears to be an increased risk of stenosis when the divided appendix is used. It is important to recognized that this problem can be solved with dilatation and a period of indwelling catheter without surgical revision. $^{(12)}$

The umbilicus and the lower abdomen have been the commonest sites of the stoma on the abdominal wall. The simplest stomas are created by direct anastomosis of the intestinal conduit to the skin, or using a V-flap combined with spatulation of the intestinal conduit. ${ }^{(13)}$

Stomal stenosis can occur in $29 \%$ of Mitrofanoffs and is less common with Monti conduit and umbilical stomas. ${ }^{(14)}$ We had two cases of stoma stenosis, both resolved with a simple surgery (circular incision and resection of the fibrosis), after two sessions of unsuccessful dilations.

Narayanaswamy et al. ${ }^{(15)}$ suggested that difficulty with catheterization was more likely to occur with a Yang-Monti conduit. In their study, $26 \%$ of patients with appendicovesicostomies, mostly sited in the right lower quadrant, had problems with CIC (clear intermittent catheterization), whereas $60 \%$ of patients with an ileo-vesicostomies had problems catheterizing their channel. Only half of these Monti channels were found to be stenotic. Lemelle et al. ${ }^{(16)}$ also compared Yang-Monti (ileum and sigmoid) and appendix channels following the Mitrofanoff and Malone principles, in a study of 65 conduits. At 5-years follow up, $94 \%$ of channels were still in use Castellan et al. ${ }^{(17)}$ also found no difference in the incidence of complications in Yang-Monti channels (23\%) versus appendix conduit (21\%) at a mean follow up of 4 years.

The stenotic conduit may be evaluated endoscopically, whereby an appropriately sized cystoscope is inserted retrogradely into the conduit via the abdominal stoma. ${ }^{(18)}$ Endoscopy allows differentiation between a true stenosis requiring dilatation or revision.

Another surgical complication that we had was urinary incontinence through the bladder neck (re-opened) in two cases. Bladder neck closure is an irreversible procedure requiring compliance catheterization of a cutaneous stoma, and historically has been reserved for intractable incontinence after prior failed procedures. ${ }^{(19)}$

In a review, Dave and Khoury summarized outcomes after surgical management of the bladder neck in children with complex incontinence and neurogenic bladder. ${ }^{(20)}$ Continence was achieved after bladder neck injection in $0 \%$ to $43 \%$ of patients, $47 \%$ to $88 \%$ after bladder neck slings and $57 \%$ to $91 \%$ for bladder neck reconstruction. ${ }^{19,20)}$

The high variability of results in their analysis was partially explained by a significant heterogeneity of surgical approaches and techniques as well as differing definitions of continence.

In 2012, Kavanagh et al. ${ }^{(19)}$ achieved a continence rate of $96 \%$ after bladder neck closure in a patient population with a variety of diagnosis after a median follow-up of 69 months. However, this high rate of continence comes with a price and the Kavanagh et al. revision was not trivial. Although initial failure of the closure itself occurred in only 1 patient (4\%), the need for further urological interventions was $39 \%$ overall. The most common cause of surgical intervention after bladder neck closure is related to bladder and renal calculi ( $11 \%$ each).

In our serie, we found less than $10 \%$ of bladder neck closure complications (1 patient of 9) with persistent urinary incontinence, even after three re-operations. Disadvantages include the true challenging to access the urinary tract in case of stone formation (particularly for renal, ureteral and bladder lithiasis). ${ }^{(19)}$

One patient of the study developed urinary infection and sepsis at $21^{\circ}$ postoperative day. He was treated with antibiotics at the intensive unit care. Routinely we did not use prophylactic antibiotics. Ten years after introducing the concept of CIC, Lapides and colleagues ${ }^{(21)}$ published a follow up study of 255 children on CIC, and noted that although $56 \%$ of patients showed bacteriuria, only $11 \%$ actually developed a symptomatic urinary tract infection.

There now seems to be a general consensus that asymptomatic bacteriuria is not treated with antibiotics. ${ }^{(22,23)}$ A randomized, controlled trial has shown that it is also not necessary,on CIC, to use prophylactic antibiotics. ${ }^{(24)}$

The frequent need for re-operation is well recognized as well as the optimal choice of procedure, location of stoma and site of implantation into the bladder continues to be a matter of debate. ${ }^{(25)}$

Reconstruction to achieve continence has been assumed to improve health-related quality of life. Early evaluation of small numbers of patients undergoing reconstruction including bladder augmentation do not always show improved status on objective questionnaires compared with preoperative studies or control patients without surgery despite what generally would be considered to be good clinical results. $^{(26,27)}$

Patient-reported scores also do not always correlate with those noted by their parents. Most evaluation of surgical techniques to date has focused on results and complications from the perspective of surgeons. Future evaluation should 
include objective, patient-reported consideration. Tools to acquire that information must be validated for longitudinal study of these patients and their disease processes.

Although bladder augmentation with continent urinary diversion works well for most patients who require it, newer medical regimens and neuromodulation may prove effective for some patients who presently do not respond to conservative measures. ${ }^{(28)}$

\section{Conclusions}

The association of Mitrofanoff's principle and Monti's technique(as idealized by Rodrigues $\mathrm{Jr}^{(7)}$ ) is safe, feasible, and a very useful alternative in urologic cases (i.e., severe and untractable urethral stenosis and low compliance neurogenic bladder) of continent urinary diversion when the ileocecal appendix is too short to reach the skin (i.e., obese patients).

\section{References}

[1] Lapides J, Diokno AC, Silber SJ, Lowe BS. Clean intermitente self-catheterization in the treatment of urinary tract disease. J Urol. 1972, Mar;107(3):458-461.

[2] Mitrofanoff P. Trans-appendicular continent cystostomy in the management of the neurogenic bladder. ChirPediatr 1980; 21: 297-305.

[3] Yang WH. Yang needle tunneling technique in creating antireflux and continent mechanisms. J Urol. 1993;150:830-834

[4] Monti PR, Lara RC, Dutra MA, de Carvalho JR. New techniques for construction of efferent conduits based on the Mitrofanoff principle. Urology 1997;49:112-115.

[5] Farrugia MK, Malone PS. Educational article: the Mitrofanoff procedure. J Pediatric Urol. 2010,6: 330-337.

[6] Blaivas JG, et al. Detrusor-external sphincter dyssynergia. J Urol. 1981, Apr; 125(4): 542-544.

[7] Rodrigues Jr AA, Cassini MF, TucciJr S, Cologna AJ, Reis RB, Martins ACP, Suaid HJ. Using Mitrofanoff's principle and Monti's technique as a surgical option for bladder augmentation with a continent stoma: a case report. J Med Case Report 2011, 5:49-51.

[8] Hosseini J, Kaviani A, Mazloomfard MM, Golshan AR. Monti's procedure as an alternative technique in complex urethral distraction defect. IntBraz J Urol 2010, 36(3); 317326.

[9] Coffey RC. Physiologic implantation of the severed ureter or common bile duct into the intestine. JAMA 191;56:397403.

[10] Eshghi M, Bronsther B, Ansong K, Hanna MK, Smith AD. Technique and trial of continent ileocystostomy. Urology 1986 Feb;27(2):112-116.

[11] Ardelt PU, Woodhouse CRJ, Riedmiller H, Gerharz EW. The efferent segment in continent cutaneous urinary diversion: a comprehensive reviem of the literature. BJUInt. 2011;109:288-297.
[12] Piaggio L, Myers S, Figueroa T E, Barthold J S, Gonzalez R Influence of type of conduit and site of implantation on the outcome of continent catheterizable channels. J PediatrUrol 2007;3:230-234.

[13] Van Savage JG, Khoury AE, McLorie GA, Churchill BM. Outcome analysis of Mitrofanoff principle applications using appendix and ureter to umbilical and lower quadrant stomal sites. J Urol 1996;156:1794e7.

[14] McAndrew HF, Malone PS. Continent catheterizable conduits: which stoma, which conduit and which reservoir? BJU Int. 2002;89:86-89.

[15] Narayanaswamy B, Wilcox DT, Cuckow PM, Duffy PG, Ransley PG. The Yang-Monti channel and appendix for continent diversion in the Mitrofanoff and Malone principles. BJU Int. 2001;87:861-865.

[16] Lemelle JL, Simo AK, Schmitt M. Comparative study of the Yang-Monti channel and apêndix for continent diversion in the Mitrofanoff and Malone principles. J Urol. 2004;172(5 Pt 1):1907-1910.

[17] Castellan MA, Gosalbez R, Labbie A, Ibrahim E, DiSandro M. Outcomes of continent catheterizable stomas for urinary and diversion: their nature and timing. $\mathrm{J}$ Urol. 2008;180(Suppl. 4):1856-1860.

[18] Roth CC, Donovan BO, Tonkin JB, Klein JC, Frimberger D, Kropp BP. Endoscopic injection of submucosalcatheterizable channels. J Pediatr Urol. 2009;5:265-268.

[19] Kavanagh A, Afshar K, Scott H, MacNeily AE. Bladder neck closure in conjunction with enterocystoplasty and Mitrofanoff diversion for complex incontinence: closing the door for good. J Urol. 2012;188: 1561-1566.

[20] Dave S and Khoury AE. Bladder outlet surgery for incontinence and neurogenic bladder. AUA Up-date Series 2010; 29 Lesson 27.

[21] Kass EJ, Koff SA, Diokno AC, Lapides J. The significance of bacilluria in children on long-term intermittent catheteriza- tion. J Urol 1981;126:223e5.

[22] Blok BF, Karsenty G, Corcos J. Urological surveillance and management of patients with neurogenic bladder: results of a survey among practicing urologists in Canada. Can J Urol 2006;13:3239e43.

[23] Van Nieuwkoop C, Den Exter PL, Elzevier HW, Den Hartigh J, Van Dissel JT. Intravesical gentamicin for recurrent urinary tract infection in patients with intermittent bladder catheterization. Int $\mathrm{J}$ Antimicrob Agents, 2010;36(6):485-490.

[24] Clarke SA, Samuel M, Boddy SA. Are prophylactic antibiotics necessary with clean intermittent catheterization? A randomized controlled trial. J PediatrSurg 2005;40:568e71.

[25] Franc-Guimond J, Gonzalez R. Effectiveness of implanting catheterizable channels into intestinal segments. J PediatrUrol 2006;17:1088-1091.

[26] Macneily AE, Morrell J, Secord S. Lower urinary tract reconstruction for spina bifida - does it improve health related quality of life? J Urol. 2005;174(4 Pt 2):1637-1643. 
[27] Parekh AD, Trusler LA, Pietsch JB, Byrne DW, et al. Prospective, longitudinal evaluation of health related quality of life in the pediatric spina bifida population undergoing reconstructive urological surgery. J Urol. 2006; 176(4 Pt
2):1878-1882.

[28] Aslan AR, Kogan BA. Conservative management in neurogenic bladder dysfunction. CurrOpin Urol. 2002;12(6):473-477. 